\title{
Vitamin D and Diabetic Retinopathy in Indian adults with Type 2 Diabetes Mellitus
}

\author{
Dinesh R.B. ${ }^{1}$, R. Anil Kumar. ${ }^{2}$ \\ ${ }^{1}$ Dr. Dinesh R B., Assistant Professor, ${ }^{2}$ Dr. Anil Kumar. R, Assistant Professor; both authors are attached with \\ Department of Vitreo Retina and Diabetology, Karnataka Institute of Endocrinology and Research (Autonomous Institute \\ of Dept of Medical Education, Govt of Karnataka), SJICR Campus, Jayanagar $9^{\text {th }}$ block, Bangalore.
}

Corresponding Author: Dr. Dinesh R B., Consultant, Department of Vitreo Retina, Karnataka Institute of Endocrinology and Research (Autonomous Institute of Dept of Medical Education, Govt of Karnataka), SJICR Campus, Jayanagar $9^{\text {th }}$ block, Bangalore- 560069. Email: dinirb@gmail.com

\begin{abstract}
Objective: To find an association with Vitamin D levels and Diabetic retinopathy (DR). Methods: In a prospective clinical study, 412 Type 2 DM patients were evaluated for their ophthalmic findings. All patients underwent complete ophthalmic examination including detailed history, best corrected visual acuity, slit lamp examination, indirect ophthalmoloscopy and +90D lens biomicroscopy. All relevant blood investigation for evaluation of glycemic status including Vitamin D was done on first presentation. Results: Among the 412 patients that were examined, thepercentage of patients with $\mathrm{HbA} 1 \mathrm{C}<6.4$ was $15 \%$, 6.5- 8.0 was $31 \%$ and $>8.0$ was $54 \%$. Among 222 patients with $>5$ years duration of DM, 95(43\%) had HbA1C >8.0. Among 96 patients with 5-10 years duration of DM, 67 (70\%) had HbA1C .8.0. Among 94 patients with $>10$ years duration of DM, 59(63\%) had HbA1C $>8.0$, with a significant $\mathrm{P}$ value of $<0.001$. Among 412 patients, 7\% had vitamin D levels $>30$, 13\% had levels between $20-30$ and $80 \%$ had $<20$. Asignificant $\mathrm{P}$ value of $<0.001$ was seen with respect to association of DR with HbA1C levels. Conclusions: Type 2 DM patients with retinopathy were found to have significantvitamin D deficiency as compared to those without retinopathy.
\end{abstract}

Key words: Vitamin D levels, HbA1C, Diabetic retinopathy, Duration of DM

\section{Introduction}

Vitamin D deficiency (VDD) is highly prevalent worldwide. Serum 25-hydroxy-vitamin D3 (25(OH)D) is a better indicatorof vitamin $\mathrm{D}$ sufficiency than the active hormone, that is, 1,25-dihydroxy-vitamin D3. Therefore, the serum concentration of $25(\mathrm{OH}) \mathrm{D}$ is widely accepted as a goodindicator of the status of vitamin $\mathrm{D}$ in a given subject. The main biological actions of vitamin $\mathrm{D}$ include the maintenance of mineral homeostasis and the regulation of bone remodelling.

However, there is a vast arrayof pleiotropic actions of this vitamin that were already recognized more than two decades ago. This area of investigation led to improved knowledge on the potential role of vitamin D on glucose homeostasis and in the pathogenesis of type 2 diabetes. Multiple studies have previously shown that vitamin D deficiency is highly prevalent in type 1 and type 2 diabetes. Additionally, there is a growing interest on the

Manuscript received: $8^{\text {th }}$ April 2018

Reviewed: $18^{\text {th }}$ April 2018

Author Corrected: $25^{\text {th }}$ April 2018

Accepted for Publication: $30^{\text {th }}$ April 2018 potential role of vitamin in the development of diabeticmicro- and macroangiopathic complications. [1]. Diabetic retinopathy (DR), which is among the most common diabetes complications which affects more than 300 million individuals in the world with significant morbidity and mortality worldwide. Major risk factors for DR include a longer diabetes duration, age, smoking, poor glycemic control, and hypertension, which have been strongly and consistently associated with DR across populations [2].

In parallel to the increase in the prevalence of diabetes mellitus, there has been a resurgence of vitamin D deficiency worldwide, and much evidence have suggested that VDD is involved in the development of various diseases including diabetes, cardiovascular disease, cancer, and autoimmune diseases. Recent studies have shown that Vitamin D has inhibitory effects on inflammation and proliferation in endothelial cells, and angiogenesis, which are involved in the development of DR. [3,4]. In addition, studies have also 
shown that Vitamin D receptor (VDR) is expressed in retina, and VD has direct inhibitory effects on the development of DR in experimental animal models $[5,6,7]$.

Albert et al. revealed that VD inhibits retinal neovascularisation in a mouse oxygen-induced ischemic retinopathy model.

Ren et al. revealed that VD has protective effects on DR by inhibiting vascular endothelial growth factor (VEGF) and transforming growth factor-b1 (TGF-b1) in the retinas of diabetic rats.

In addition, human genetic studies have shown that polymorphisms of VDR gene are associated with DR. [2] Somerecent epidemiological studies suggested asignificant association between low vitamin Dstatus and increased prevalence of diabetic-microangiopathy $[8,9,10]$.

\section{Methods}

Place of study: Karnataka Institute of Endocrinology and Research

Type of study: Prospective clinical study

Participants: 412 Type 2 DM patients were evaluated for their ophthalmic findings and relevant investigations for the evaluation of DM

\section{Original Research Article}

Sampling methods: All patients underwent complete ophthalmic examination including detailed history, best corrected visual acuity, slit lamp examination, indirect ophthalmoloscopy and +90D lens biomicroscopy.

Relevant blood investigations including FPS, PPPS, HbA1C and Vitamin D were done

A thorough medical examination was carried out by a physician to rule out any systemic disease.

Inclusion criteria: All patients aged above $18 \mathrm{yrs}$ and confirmed to be Type 2 DM were included in the study.

\section{Exclusion criteria}

1) All patients less than 18 yr old

2) Type $1 \mathrm{DM}$ patients

3) Any patient with a history of Vitamin D supplementation were excluded

Statistical methods: The statistical analysis was performed by STATA 11.2 (College Station TX USA).

Chi square test has been used to measure the association between the duration of diabetes with $\mathrm{HbA} 1 \mathrm{C}$ and Vitamin D levels with duration of diabetes, Hb1C and these are expressed as frequency and percentage.

\section{Results}

Table-1: Duration of Type 2 DM

\begin{tabular}{|c|c|c|}
\hline & Number of Cases & Percentage \\
\hline $0-5$ Years & 222 & $54 \%$ \\
\hline $5-10$ Years & 96 & $23 \%$ \\
\hline$>10$ Years & 94 & $23 \%$ \\
\hline Total & $\mathbf{4 1 2}$ & \\
\hline
\end{tabular}

The percentage of patients with duration of Type 2 DM with $0-5$ years was $54 \%, 5-10$ years was $23 \%$ and $>10$ years was $23 \%$.

Table- 2: HbA1C levels

\begin{tabular}{|c|c|c|}
\hline HbA1C & Number of Cases & Percentage \\
\hline$<6.40$ & 62 & $31 \%$ \\
\hline $6.5-8.0$ & 129 & $54 \%$ \\
\hline$>8.0$ & 221 & \\
\hline Total & $\mathbf{4 1 2}$ & \\
\hline
\end{tabular}

The percentage of patients with $\mathrm{HbA} 1 \mathrm{C}<6.4$ was $15 \%, 6.5-8.0$ was $31 \%$ and $>8.0$ was $54 \%$. 
Table-3: Duration of Type 2 DM with HbA1C

\begin{tabular}{|c|c|c|c|c|c|}
\hline & \multicolumn{3}{|c|}{ HbA1C } & \multirow[b]{2}{*}{ Total } & \multirow[b]{2}{*}{ P-Value } \\
\hline Duration of Diabetes & $<6.40$ & $6.5-8.0$ & $>8.0$ & & \\
\hline$<5$ Years & $49(22 \%)$ & $78(35 \%)$ & $95(43 \%)$ & 222 & \multirow{3}{*}{$<0.001$} \\
\hline 5-10 Years & $7(7 \%)$ & $22(23 \%)$ & $67(70 \%)$ & 96 & \\
\hline$>10$ Years & $6(6 \%)$ & $29(31 \%)$ & $59(63 \%)$ & 94 & \\
\hline Total & 62 & 129 & 221 & 412 & \\
\hline
\end{tabular}

Among 222 patients with $>5$ years duration of DM, 95(43\%) had HbA1C >8.0. Among 96 patients with 5-10 years duration of DM, 67(70\%) had HbA1C .8.0. Among 94 patients with>10 years duration of DM, 59(63\%) had HbA1C $>8.0$, with a significant $\mathrm{P}$ value of $<0.001$

Table-4: No of cases with DR.

\begin{tabular}{|c|c|c|}
\hline & Number of Cases & Percentage \\
\hline NO DR & 294 & $71 \%$ \\
\hline Mild NPDR & 75 & $6 \%$ \\
\hline Moderate NPDR & 24 & $2 \%$ \\
\hline Severe NPDR & 10 & $2 \%$ \\
\hline PDR & 9 & \\
\hline Total & $\mathbf{4 1 2}$ & $2 \%$ \\
\hline
\end{tabular}

Among 412 patients $71 \%$ had no diabetic retinopathy (DR), 18\% had mild non proliferative diabetic retinopathy (NPDR), 6\% had moderate NPDR, 2\% had severe NPDR and 2\% had proliferative diabetic retinopathy (PDR)

Table-5: Vitamin D Levels.

\begin{tabular}{|c|c|c|}
\hline & Number of Cases & Percentage \\
\hline Normal $(>30)$ & 27 & $13 \%$ \\
\hline Insufficiency $(20-30)$ & 55 & $80 \%$ \\
\hline Deficiency $(<20)$ & 330 & \\
\hline Total & $\mathbf{4 1 2}$ & \\
\hline
\end{tabular}

Among 412 patients, 7\% had vitamin D levels $>30,13 \%$ had levels between $20-30$ and $80 \%$ had $<20$.

Table-6: HbA1C with Vitamin D levels.

\begin{tabular}{|c|c|c|c|c|c|}
\hline & Normal & Insufficiency & Deficiency & Total & P-Value \\
\hline$<6.40$ & $5(19 \%)$ & $13(24 \%)$ & $44(13 \%)$ & 62 & \multirow{3}{*}{0.281} \\
\hline $6.5-8.0$ & $10(37 \%)$ & $14(25 \%)$ & $105(32 \%)$ & 129 & \\
\hline$>8.0$ & $12(44 \%)$ & $28(51 \%)$ & $181(55 \%)$ & 221 & \\
\hline Total & 27 & 55 & 330 & 412 & \\
\hline
\end{tabular}

Among 330 patients with Vitamin d D deficiency, 13\% had HbA1C $<6.40,32 \%$ had $6.5-8.0$ and $55 \%$ had $>8.0$ 
Table-7:

\begin{tabular}{|c|c|c|c|c|c|}
\hline \multirow[b]{2}{*}{$\begin{array}{c}\text { Duration of } \\
\text { Diabetes }\end{array}$} & \multicolumn{3}{|c|}{ VitaminD Levels } & \multirow[b]{2}{*}{ Total } & \multirow[b]{2}{*}{ P-Value } \\
\hline & Normal & Insufficiency & Deficiency & & \\
\hline$<5$ Years & $14(6 \%)$ & $29(13 \%)$ & $179(81 \%)$ & 222 & \multirow{3}{*}{0.775} \\
\hline 5-10 Years & $7(7 \%)$ & $10(10 \%)$ & $79(82 \%)$ & 96 & \\
\hline$>10$ Years & $6(6 \%)$ & $16(17 \%)$ & $72(77 \%)$ & 94 & \\
\hline Total & 27 & 55 & 330 & 412 & \\
\hline
\end{tabular}

Among 330 patients with Vitamin D deficiency, 179 had $<5$ years duration of DM, 79 had 5-10 years and 72 had $>10$ years duration of DM

Table-8: Diagnosis compared with HbA1C by Vitamin D levels

\begin{tabular}{|c|c|c|c|c|c|}
\hline & \multicolumn{3}{|c|}{ HbA1C } & \multirow[b]{2}{*}{ Total } & \multirow[b]{2}{*}{ P-Value } \\
\hline & $\leq 6.40$ & $6.5-8.0$ & $>8.0$ & & \\
\hline \multicolumn{6}{|l|}{ Normal } \\
\hline NO DR & 5 & 7 & 8 & 20 & \multirow{5}{*}{0.668} \\
\hline Mild NPDR & 0 & 2 & 2 & 3 & \\
\hline Moderate NPDR & 0 & 1 & 2 & 3 & \\
\hline Severe NPDR & 0 & 0 & 1 & 1 & \\
\hline \multicolumn{5}{|l|}{ PDR } & \\
\hline \multicolumn{6}{|l|}{ Insufficiency } \\
\hline NO DR & 12 & 10 & 20 & 42 & \multirow{5}{*}{0.645} \\
\hline Mild NPDR & 1 & 2 & 5 & 8 & \\
\hline Moderate NPDR & 0 & 1 & 2 & 3 & \\
\hline Severe NPDR & 0 & 1 & 0 & 1 & \\
\hline PDR & 0 & 0 & 1 & 1 & \\
\hline \multicolumn{6}{|l|}{ Deficiency } \\
\hline NO DR & 39 & 86 & 107 & 232 & \multirow{5}{*}{$<0.001$} \\
\hline Mild NPDR & 4 & 47 & 43 & 64 & \\
\hline Moderate NPDR & 1 & 1 & 16 & 18 & \\
\hline Severe NPDR & 0 & 1 & 7 & 8 & \\
\hline PDR & 0 & 0 & 8 & 8 & \\
\hline
\end{tabular}

Asignificant $\mathrm{P}$ value of $<0.001$ was seen the association of DR with HbA1C levels

\section{Discussion}

Vitamin D deficiency (VDD) has been implicated in the development of diabetes complications, specifically diabetic retinopathy (DR). It has a number of metabolites the 2 most important of which are 1,25dihydroxyvitamin D3 $(1,25(\mathrm{OH}) 2 \mathrm{D} 3)$ and 25 vitamin hydroxyapatite $\{25(\mathrm{OH}) \mathrm{D}\}$. The serum concentrations of both have been used to quantify vitamin D deficiency and study its relationship withdiabetic retinopathy. In a mouse model of Ischaemic retinopathy, 1,25- dihydroxyvitamin D3 $(1,25(\mathrm{OH}) 2 \mathrm{D} 3)$ has been shown to inhibit retinal neovascularisation and in cell cultures it inhibited endothelial cell proliferation, most likely due 
to its interaction with vascular endothelial growth factor (VEGF). In our study, among 412 patients, 330 (80\%) patients had Vitamin D deficiency.

Genetic studies have revealed that vitamin D receptor (VDR) is present in the human retina, and polymorphisms of VDR are relatedto retinopathy risk in type 1 diabetes. For example, the Fok 1 single nucleotide polymorphism of the VDR gene has been associated with increased transcriptional activity of the VDR gene and less severe diabetic retinopathy and Taq 1 polymorphism of VDR gene with decreased incidence of retinopathy [11].

A large American study looked at 1790 diabetics in United States of America (USA), and the percentage of individuals with vitamin Ddeficiency increased with severity of retinopathy. However, the study did not demonstrate a statistically significant relationship betweenseverity of retinopathy and serum 25(OH)D concentration [8].

The characteristic feature of diabetic retinopathy is the appearance of vascular lesions of increasing severity, ending up in the growth of new vessels (neovascularisation). Vitamin D has anti-inflammation properties and inhibits vascular smooth muscle cell growth and effects on the expression of transforming growth factor $\beta 1$ Vitamin D is an important regulator of hundreds of genes regulating key biological processes from cell division to apoptosis. It is well known that poor glycemic control is a risk factor for the development and progression of DR, and vitamin D deficiency has been shown to impair insulin synthesis and secretion in animal models of diabetes [12]. On the other hand, an optimal concentration of vitamin D is strongly proven to be necessary for efficient insulin secretion and function, and vitamin D receptors (VDR) are ubiquitously expressed in every human tissue, including retina.

Active vitamin $\mathrm{D}$ mediates its biological function by binding to vitamin $\mathrm{D}$ receptors. Vitamin $\mathrm{D}$ receptors have been found to be associated with insulin secretion and sensitivity, and have been identified in pancreatic beta cells.

Additionally, some genes associated with the development of diabetic retinopathy have been found, such as Bsm1, rs2228570, and TT. So, vitamin D status is related with the development and progression of diabetic retinopathy among type 2 diabetes patients. [13].

\section{Original Research Article}

A Turkish study carried out in 2000 compared serum $25(\mathrm{OH}) \mathrm{D}$ between 66 diabetic patients and 20 non diabetics and found it to besignificantly lower in diabetics. The study also found an inverse relationship between the severity of retinopathy and serum $25(\mathrm{OH})$ Dconcentrations which was lowest in patients with proliferative diabetic retinopathy (PDR).

The authors suggested that measurement of serum $25(\mathrm{OH})$ Dmay be helpful in predicting severity of DR in diabetic patients [9] Suzuki, etal. studied this relationship in Japanesetype 2 diabetics and found patients with proliferative retinopathy had lower serum $25(\mathrm{OH}) \mathrm{D}[14]$.

Hala., et al. found this to be true in 136 Lebanese type 2 diabetics with retinopathy, and vitamin D levels were an independent predictor of retinopathy [15]. In China 1520 type 2 diabetics with retinopathy had low serum $25(\mathrm{OH})$ D concentrations and this link was moresignificant in those with sight-threatening retinopathy [16]. This study found a two-fold increase in sightthreatening retinopathy amongsubjects with serum 25 (OH)D below $15.57 \mathrm{ng} / \mathrm{ml}$ (normal range 20 - 50ng/ml) [17].

Suzuki et al conducted the observational study in 581 Japanese patients with type 2 diabetes mellitus and 51 normal subjects, and analyzed the relationship between serum 25-hydroxyvitamin D (25-OHD) concentration and the clinical features associated with type 2 diabetes.

Mean serum 25-OHD concentration in type 2 diabetes patients was $17.0+/-7.1 \mathrm{ng} / \mathrm{ml}$ (Mean +/- SD) in winter, and was not statistically different from normal population $(17.5+/-3.6 \mathrm{ng} / \mathrm{ml})$. The prevalence of hypovitaminosis D $(<20 \mathrm{ng} / \mathrm{ml})$ was $70.6 \%$. Serum concentrations of 25-OHD were associated with HbA1c $(\mathrm{P}=0.013)$, age $(\mathrm{P}=0.070)$ and serum albumin $(\mathrm{P}<$ $0.001)$, but were not related to BMI or the duration of diabetes. The levels of 25-OHD were significantly lower in the population with apparent micro vascular complications [4].

Gungor., et al. studied retinal nerve fibre layer (RNFL) thickness in type 2 diabetics with early diabetic retinopathy with and without VDD, and found low serum $25(\mathrm{OH}) \mathrm{D}$ concentrations contribute to RNFL thinning. It is well known that in addition to vascular changes the earliest stages of DR feature neuro degenerative processes such as loss of ganglion cells and thinning of retinal layers. The studyindicates that vitamin D has a neuroprotective component [18]. 


\section{Original Research Article}

Among 64 patients with Vitamin D deficiency with Mild NPDR, 47 patients had HbA1C between 6.5-8.0 and 43 patients had HbA1C $>8.0$. Among 18 patients with VDD with Moderate NPDR, one had HbA1C between 6.5-8.0 and 16 had $\mathrm{HbA} 1 \mathrm{C}$ of $>8.0$. Among 8 patients with VDD with Severe NPDR, one had HbA1C between $6.5-8.0$ and 7 had $\mathrm{HbA} 1 \mathrm{C}$ of $>8.0$. Among 8 patients with VDD with PDR, all 8 had HbA1C $>8.0$.

In our study we found a significant correlation between Vitamin D deficiency and severity of diabetic retinopathy clearly establishing the role of Vitamin D in the pathology and severity of diabetic retinopathy.

\section{Conclusions}

Type 2 DM patients with retinopathy were found to have significant vitamin D deficiency and higher HbA1C levels as compared to those without retinopathy, thus signifying the association of a higher frequency of vitamin D deficiency and higher levels of HbA1C (>8.0) with diabetic retinopathy These findings reveal the potential role of vitamin $\mathrm{D}$ in the pathogenesis of diabetic retinopathy.

This study throws light on the strong association between low Vitamin D levels and higher levels of HbA1C levels, thereby emphasising the need for a two pronged approach of glycemic control and correction of vitamin $\mathrm{D}$ deficiency resulting in better management of diabetic retinopathy.

\section{Abbreviations-}

VDD-Vitamin D deficiency.

DM-Diabetes mellitus.

DR-Diabetic retinopathy.

RNFL-Retinal nerve fibre layer.

VDR-Vitamin D receptor.

Funding: Nil, Conflict of interest: None

Permission of IRB: Yes

\section{References}

1. Nuria Alcubierre, Joan Valls, Esther Rubinat, Gonzalo Cao, Aureli Esquerda, Alicia Traveset, Minerva Granado- Casas, Carmen Jurjo, and Didac Mauricio1.Vitamin D Deficiency Is Associated with the Presence and Severity of Diabetic Retinopathy in Type2 Diabetes Mellitus Journal of Diabetes Research Volume 2015, Article ID 374178, 7 pageshttp://dx.doi. org $/ 10.1155 / 2015 / 374178$
2. Fang Liang1, Kuixiang Wang, Hongxia Zhang, Jian Zhang, Xinsheng Nie, Zhanxiu Zhang, Zhenfeng Shi. Serum 25-hydroxy vitamin D levels and diabetic retinopathy: a systematic meta-analysisInt J Clin Exp Pathol 2016; 9 (12): 12843-12848. www.ijcep.com / ISSN: 1936-2625/IJCEP0036602

3.Robinson JG, Manson JE, Larson J, Liu S, Song Y, Howard BV, Phillips L, Shikany JM, Allison M, Curb JD, Johnson KC, Watts N. Lack of association between $25(\mathrm{OH}) \mathrm{D}$ levels and incident type 2 diabetes in older women. Diabetes Care 2011 Mar; 34(3):628-34. doi: 10.2337/dc10-1632. Epub 2011 Feb 2.

4. Suzuki A, Kotake M, Ono Y, Kato T, Oda N, Hayakawa N, Hashimoto S, Itoh M. Hypo vitaminos is $\mathrm{D}$ in type 2 diabetes mellitus: Association with microvascular complications and type of treatment. Endocr J2006 Aug; 53 (4):503-10. Epub 2006 Jul 10.

5. Zhong X, Du Y, Lei Y, Liu N, Guo Y, Pan T. Effects of vitamin $\mathrm{D}$ receptor gene polymorphism and clinical characteristics on risk of diabetic retinopathy in Han Chinese type 2 diabetes patients. Gene 2015 Jul 25; 566 (2): 212-6. doi: 10.1016/j.gene.2015.04.045. Epub 2015 Apr 18.

6. Liu Z, Liu L, Chen X, He W, Yu X. Associations study of vitamin $D$ receptor gene polymorphisms with diabetic microvascular complications: a meta-analysis. Gene 2014 Aug 1;546(1):6-10. doi: 10.1016/j.gene. 2014. 05.052. Epub 2014 May 24.

7. Ouchi M, West K, Crabb JW, Kinoshita S, Kamei M. Proteomic analysis of vitreous from diabetic macular edema. Exp Eye Res 2005 Aug;81(2):176-82.

8. Patrick PA, Visintainer PF, Shi Q, et al. Vitamin D and retinopathy inadults with diabetes mellitus. Arch Ophthalmol 2012 Jun; 130 (6):756-60. doi: 10.1001/ archophthalmol. 2011.2749.

9. Aksoy H, Akçay F, Kurtul N, et al. Serum 1,25 dihydroxy-vitamin D (1,25(OH)2D3), 25 hydroxyvitamin D $(25(\mathrm{OH}) \mathrm{D})$ and parathormonelevelsin diabetic retinopathy. Clin Biochem 2000 Feb; 33 (1): 47-51.

10. Diaz VA, Mainous AG, Carek PJ, et al. The association of vitamin Ddeficiency and insufficiency with diabetic nephropathy: implicationsfor health disparities. J Am Board Fam 2009 Sep-Oct; 22 (5): 5217. doi: 10.3122/jabfm.2009.05.080231. 


\section{Original Research Article}

11. Chandoshi Mukherjee. et al. Does Vitamin D Deficiency Affect Diabetic Retinopathy?: A Primary Care Survey and Literature Review. EC Ophthalmology 4.1 (2016): 451-458

12. Mathieu, C.Gysemans, C, Giulietti,A, Bouillon, R. Vitamin Danddiabetes. Diabetologia 2006 Jan;49(1): 217-8. Epub 2005 Dec 13. DOI:10.1007/s00125-0050047-9

13. The Association between Vitamin D Deficiency and Diabetic Retinopathy in Type 2 Diabetes: A MetaAnalysis of Observational StudiesBang-An Luo, Fan Gao and Lu-Lu Qin .Nutrients 2017 Mar; 9(3): 307. doi: $10.3390 /$ nu9030307

14. A. Suzuki., et al. Hypovitaminosis D in type 2 diabetes mellitus: association with microvascular complications and type of treatment. Endocrine Journal 2006 Aug;53(4):503-10. Epub 2006 Jul 10.

15. H. Ahmadieh., et al. Hypovitaminosis D in patients with type 2 diabetes mellitus: a relation to disease control and complications. International scholarly research Notices-Endocrinology ISRN Endocrinology Volume 2013 http ://dx. doi.org/10.1155/2013/641098

16. Robinson JG, Manson JE, Larson J, Liu S, Song Y, Howard BV, Phillips L, Shikany JM, Allison M, Curb JD, Johnson KC, Watts N. Lack of association between 25(OH) D levels and incident type 2 diabetes in older women. Diabetes Care 2011 Mar; 34 (3):628-34. doi: 10.2337/dc10-1632. Epub 2011 Feb 2.

17. R. He., et al. Vitamin D deficiency increases the risk of retinopathy in Chinese patients with Type 2 diabetes. Diabetic Medicine 2014 Dec; 31(12):1657-64. doi: 10. 1111/dme.12581. Epub 2014 Oct 10.

18. A. Gungor. et al. Retinal Nerve Fiber Layer Thickness in Early-Stage Diabetic Retinopathy with Vitamin D Deficiency". Investigative Ophthalmology \& Visual Science 56 (11): 6433-6437. doi: 10.1167/ iovs. 15-16872

\section{How to cite this article?}

Dinesh R.B, R. Anil Kumar. Vitamin D and Diabetic Retinopathy in Indian adults with Type 2 Diabetes Mellitus. Int J Med Res Rev 2018;6 (04):221-227. doi:10.17511/ijmrr. 2018.i04.04. 